Background/introduction In 2010 Quality Innovation Productivity and Prevention (QIPP) was introduced to enable the NHS to provide cost efficient services. The 2013 BHIVA Standards of Care include the need to provide quality cost effective care.

Aim(s)/objectives Our aims were to assess whether unnecessary blood tests were undertaken during routine HIV assessments; to ensure minimal patient disruption and cost stewardship.

Methods Standards were established using current BHIVA and HIV CRG CD4 blood monitoring guidelines. A retrospective audit was carried out on patients attending for a routine review between the $1^{\text {st }}$ of December 2014 and the $31^{\text {st }}$ of January 2015 who had been on treatment for at least three months. Laboratory medicine cost data was ascertained.

Results 41 patient's notes and HARS entries were reviewed, $71 \%, 90 \%$, and $83 \%$ had their CD4 count, full blood count and lipids, respectively, unnecessarily requested. 44\%, 39\%, 56\% of the Syphilis, Hepatitis B and Hepatitis C blood tests respectively, were either not done as per the standards or inappropriately requested. There was a potential cost saving of over $£ 1300$ on blood tests where over 30\% were unnecessarily requested.

Discussion/conclusion Blood monitoring should not be a tick box exercise. Requesting unnecessary blood tests is not only costly but minor changes in the results may lead to unnecessary patient intervention. Clinic proformas can be used as an aid to whether investigations are required. Testing for Syphilis, Hepatitis B and C outside of the recommended standards should be guided by sexual histories taken during consultation.

\section{P024 CLINICAL CHARACTERISTICS OF HERPES SIMPLEX VIRUS URETHRITIS COMPAERD WITH CHLAMYDIA URETHRITIS AMONG MEN: A CASE CONTROL STUDY}

\begin{abstract}
1,3Jason Ong, 'Anna Morton*, ${ }^{1}$ Helen Henzel, ${ }^{1}$ Karen Berzins, ${ }^{2} J u l i a n$ Druce, ${ }^{1,3}$ Christopher Fairley, ${ }^{1,3}$ Catriona Bradshaw, ${ }^{4}$ Jane Hocking, ${ }^{1,3}$ Marcus Chen. ${ }^{1}$ Melbourne Sexual Health Centre, Melbourne, Australia; ${ }^{2}$ Victorian Infectious Disease Reference Laboratory, Melbourne, Australia; ${ }^{3}$ Central Clinical School, Monash University, Melbourne, Australia; ${ }^{4}$ Melbourne School of Population and Global Health, Melbourne, Australia
\end{abstract}

\subsection{6/sextrans-2016-052718.78}

Background/introduction Non-gonococcal urethritis (NGU) in males is a sexually transmitted infection commonly caused by Chlamydia trachomatis and Mycoplasma genitalium. Herpes simplex virus (HSV) has been reported as a causative agent in NGU; however, little is known about its clinical characteristics.

Aim(s)/objectives The study compared the clinical characteristics of men with HSV urethritis to those in men with chlamydial urethritis, and determined if there were any key differences.

Methods A retrospective case control study comparing the clinical and laboratory findings from men diagnosed with PCR confirmed HSV urethritis with those diagnosed with PCR confirmed chlamydial urethritis, was conducted between 2000 to 2015.

Results Eighty HSV urethritis cases were identified: 68\% (95\% CI 58-78) were HSV type 1 and 32\% (95\% CI 22-42) were HSV type 2. Compared with chlamydial urethritis, men with HSV urethritis were significantly more likely to report severe dysuria $(20 \%$ vs $0 \%, \mathrm{p}<0.01)$ or constitutional symptoms $(15 \%$ vs $0 \%, \mathrm{p}<0.01)$ and significantly less likely to report urethral discharge ( $19 \%$ vs $54 \%, \mathrm{p}<0.01)$. Men with HSV urethritis were significantly more likely to have meatitis $(62 \%$ vs $23 \%$, $\mathrm{p}<0.01)$, genital ulceration $(37 \%$ vs $0 \%, \mathrm{p}<0.01)$, and inguinal lymphadenopathy $(30 \%$ vs $0 \%, \mathrm{p}<0.01)$.
Discussion/conclusion In our study men with HSV urethritis had distinctive clinical features, not usually associated with chlamydial urethritis: severe dysuria, constitutional symptoms, meatitis, genital ulceration and lymphadenopathy. Clinicians should consider HSV when these are present.

\section{P025 IMPROVING LOCAL SEXUAL HEALTH SERVICES FOR LESBIAN, GAY, BISEXUAL AND TRANS (LGBT) PEOPLE}

Sinead Cook, Rachel Drayton*. Cardiff and Vale University Health Board, Cardiff, UK

\subsection{6/sextrans-2016-052718.79}

Background/introduction LGBT people have different care needs to other sexual health clinic attendees. Many STIs are known to disproportionately affect men who have sex with men (MSM). We wished to ascertain how to optimise LGBT, and in particular MSM, service provision by our urban sexual health clinic.

Methods 100 questionnaires were completed by attendees to the local Pride event.

Results 61 respondents self-defined as female, 34 male, 4 transman and 1 demifem. 27 (20 women, 4 men) stated their sexual partners were both male and female, 38 (12 women, 25 men) had same-sex partners, and 34 (28 women, 5 men) had opposite-sex partners only.

81 had not attended the local clinic. Reasons for this included previously living elsewhere (22), not feeling they required the service (15) or not knowing it existed (9). 67 reported they would like a specific LGBT sexual health clinic, with 63 requesting evening clinics. 9 did not want specific clinics, with 2 respondents citing concerns about discrimination. 61 felt more LGBT sexual health services outside the city centre are needed. Features they would like included web-based bookings (64), home-testing kits (49), pre-exposure prophylaxis (79) and HPV vaccination (69).

Discussion/conclusion The questionnaire was successful in capturing opinions of those who hadn't previously attended our service. However it is not possible to ascertain whether views expressed were representative of the local LGBT population as a whole and less than a third were MSM. We will consider developing a specific LGBT service in response to the survey's findings.

\section{P026 VALUE OF CONTINUING PHARYNGEAL GENPROBE APTIMA COMBO2 TRANSCRIPTION MEDIATED AMPLIFICATON (TMA) TESTING FOR CT/GC IN ADDITION TO UROGENITAL/RECTAL SWABS}

${ }^{1}$ Mrinalini Mahto*, ${ }^{2}$ Harry Mallinson. 'Macclesfield District Gen. Hospital, Macclesfield, Cheshire, UK; ${ }^{2}$ Aintree University Hospital, retired consultant Microbiology, Liverpool, UK

\subsection{6/sextrans-2016-052718.80}

Introduction BASHH guidelines say 'consider' Throat swabs (TS)/rectal swabs (RS) in females where history suggests \& to test in MSM. We were routinely testing females practicing fellatio \& MSM on throat swabs (TS) for CT/GC in addition to the genital/rectal sites.

Aim To review testing practices to look at whether TS gave extra positivity $\&$ whether it was cost effective. 
Method Retrospective extraction of data for all CT/GC TMA testing between 2011-2014, and analysis of selected records where TS \& urogenital \pm rectal sites sampled at the same visit. Results CT was detected on TS from 1.2\% of female (adding 8 extra cases), and from $0.76 \%$ of MSM (adding no extra cases) GC was detected on TS from $0.76 \%$ of females (adding 9 extra cases), and from $3.0 \%$ of males (adding 3 extra cases) In a subset of 251 females who had RS, GC was detected on TS from $3.6 \%$ adding 5 extra cases to the 4 urogenital/rectal diagnoses.

Conclusions In diagnosis of CT infection, TS find only a few extra male \& female cases For GC infection TS did increase the number of diagnoses (females from 12 to 21, males from 17 to 20). Whilst GC testing by TMA adds no cost to a genital sample which is already being tested for CT, a throat swab which is an extra sample has to be charged at full price by the Laboratory. Perhaps full price testing of TS can only be justified for groups with higher than average GC diagnoses such as MSM (3.0\%) or females with an indication for a rectal testing $(3.6 \%)$.

\section{P027 A QUALITATIVE STUDY EXPLORING THE POTENTIAL INFLUENCES OF SEXUALITY, GENDER IDENTITY, AND OCCUPATION ON HEALTH STATES AND ENGAGEMENT WITH HEALTHCARE AMONG LGBTQIA+ SEX WORKERS IN NEW ZEALAND}

Emma Dorothy Mills*, Chris Burton. University of Aberdeen, Aberdeen, UK

\subsection{6/sextrans-2016-052718.81}

Background/introduction The stigma an individual experiences in relation to their occupation, gender identity, or sexuality adversely influences health and well-being. There is however, limited literature which explores the joint influence of both sex work (a highly stigmatised occupation), and a sexual minority identity on health states and engagement with services. Preliminary work suggested that such individuals face greater risk of illhealth, and of experiencing barriers to care.

Aim(s)/objectives To explore how LGBTQIA $^{+}$sex workers perceive their occupation, sexuality, and gender identities influence their health states and access to health care.
Methods Semi-structured phone interviews were conducted with sex workers who self-identified as LGBTQIA ${ }^{+}$. Purposive sampling of participants ensured individuals were diverse in their sexuality, gender identity, and type and duration of sex work experience. The data collected during these interviews was analysed using a thematic approach.

Results Seven interviews were conducted. It was apparent that continuing social stigma directed towards sex workers and members of the LGBTQIA $^{+}$community perpetuates occupational hazards and acts as a barrier to accessing healthcare. The positive influences of a community of stigmatised peers in promoting engagement with health services was explored, including community information sharing networks and providing specific services inclusive to the needs of LGBTQIA $^{+}$sex workers.

Discussion/conclusion Whilst decriminalisation has reduced the stigma faced by many sex workers in New Zealand, disproportionate discrimination persists among those who identify as LGBTQIA $^{+}$, negatively impacting health states. The utilisation of peer networks promoting access to healthcare within this community is requiring of further research.

\section{P028 DO WE REALLY NEED TO SEND AN MSU?}

Bethanie Rooke*, Alice Baker, Sarah Barrett. Whittall Street Clinic, Birmingham, UK

10.1136/sextrans-2016-052718.82

Background/introduction Midstream urine (MSU) results create a significant workload for our clinic. MSU can diagnose urinary tract infection (UTI), but detecting asymptomatic bacteriuria or contaminants confuses management. Lower UTI is common in non-pregnant women, but MSU is unnecessary as UTI can be diagnosed clinically. Local guidelines identified four indications for MSU: women with dysuria and loin pain, urinary symptoms in pregnancy, men with dysuria and frequency/urgency, and epididymo-orchitis.

$\operatorname{Aim}(\mathbf{s}) /$ objectives To assess whether MSU is requested for appropriate indications, and to evaluate the usefulness of MSU in diagnosing and managing patients in a sexual health clinic.

\begin{tabular}{|c|c|c|c|c|c|c|c|c|}
\hline \multirow[t]{2}{*}{$\begin{array}{l}\text { Urogenital/rectal } \\
\text { diagnosis }\end{array}$} & \multicolumn{4}{|c|}{$\begin{array}{l}\text { Females: } \\
\text { Throat swab results }\end{array}$} & \multicolumn{4}{|c|}{$\begin{array}{l}\text { Males: } \\
\text { Throat swab results }\end{array}$} \\
\hline & $\mathrm{Neg}$ & Pos & Total & $\%$ Positive & Neg & Pos & Total & \% Positive \\
\hline CT Negative & 2039 & 8 & 2047 & 0.39 & 240 & 0 & 240 & 0 \\
\hline СТ Positive & 133 & 18 & 151 & 11.9 & 21 & 2 & 23 & 8.6 \\
\hline Total urogenital/rectal & 2172 & 26 & 2198 & 1.2 & 261 & 2 & 263 & 0.76 \\
\hline$\%$ Positive & & & 6.9 & & & & & 8.8 \\
\hline GC Negative & 2206 & 9 & 2215 & 0.41 & 246 & 3 & 249 & 1.2 \\
\hline GC Positive & 4 & 8 & 12 & 67 & 12 & 5 & 17 & 29 \\
\hline Total urogenital/rectal & 2210 & 17 & 2227 & 0.76 & 258 & 8 & 266 & 3.0 \\
\hline$\%$ Positive & & & 0.53 & & & & & 6.4 \\
\hline
\end{tabular}

